\title{
Digital humanities degrees and supplemental credentials in Information Schools (iSchools)
}

\author{
Peter J. Cobb ${ }^{\mathrm{a}, *}$ and Koraljka Golub ${ }^{\mathrm{b}}$ \\ ${ }^{a}$ University of Hong Kong, Hong Kong, China \\ ${ }^{\mathrm{b}}$ Linnaeus University, Sweden
}

\begin{abstract}
The digital humanities (DH) is an emerging field of teaching and research that invites modern technologies to address traditional humanities questions while simultaneously making space for humanistic critiques of those technologies. A natural relationship exists between DH and the field of information studies (the iField), particularly surrounding their common focus on the interface between humans and computers, as well as subfields such as the organization of information, libraries and archives, data preservation, and information in society. Thus, we propose that iField programs in universities should take an active role in DH education. We are particularly interested in programs that are officially Information Schools (iSchools), members of the international iSchools Organization. Our research began as part of a DH curriculum committee convened by the iSchools Organization. To support iSchool engagement in DH education, we have inventoried and analyzed the degrees and supplemental credentials offered by DH education programs throughout the world. Our study deployed multiple data collection methods, which included conducting both ad hoc and comprehensive website surveys, querying an online DH catalog, and inviting members of the iSchools Organization to participate in an online questionnaire. This work has revealed several common patterns for the current structure of DH programs, including the various types of degrees or supplemental credentials offered. We observe that iSchools have a significant opportunity to become more engaged in DH education and we suggest several possible approaches based on our research.
\end{abstract}

Keywords: Digital humanities, iSchools, iField, interdisciplinary, degrees and credentials

\section{Introduction}

For the past several decades, technology and instant communication have increasingly transformed our daily lives in all contexts - professional, commercial, academic, and beyond. Higher education must keep pace with these wider societal changes to remain relevant in any academic discipline, especially the humanities. Interdisciplinary approaches are particularly well situated to help the humanities address today's societal challenges from within universities. Information Schools (iSchools) and digital humanities (DH) programs, which operate at the intersection of humanity and technology, are naturally positioned for synergistic relationships and interdisciplinary work (Bartlett \& Dalkir, 2020; Casarosa et al., 2020). The goal of this paper is to

\footnotetext{
*Corresponding author: Peter J. Cobb, University of Hong Kong, Hong Kong, China. E-mail: pcobb@
} hku.hk.

0167-8329 (c) 2022 - The authors. Published by IOS Press. This is an Open Access article distributed under the terms of the Creative Commons Attribution-NonCommercial License (CC BY-NC 4.0 $)$. 
contribute to research that can guide universities in implementing DH education, particularly in iSchools (Terras, 2006; Spiro, 2011; Alexander \& Davis, 2012; Sula et al., 2017). Here we limit our focus to iSchools, which we define as programs that are officially members of the international iSchools Organization. Our approach is to outline potential models for offering DH education and credentials through an examination of examples worldwide. Based on our results, we recommend that iSchools take a more active role in establishing and participating in DH educational programs at their universities.

Although challenging to precisely define, the field of digital humanities is generally recognized as an engagement with computational technology to enhance research and teaching in traditional humanities fields. By bringing together the human and the computer, DH helps the humanities better address societal problems. The European Union, for example, recognizes humanities and social sciences as "essential to maximize the returns to society from investment in science and technology" (European Commission, 2016). The study of digital information takes diverse forms within universities, with programs often developing out of library science, business, or computer science departments. Here, we focus specifically on formalized academic programs in the information studies field (iField) that have opted for membership in the international iSchools Organization (iSchools Organization, 2020). As of October 2020 , the 117 iSchools at universities across the world offer coursework and degrees supported by faculty who conduct research in the iField.

This paper outlines programs that offer DH degrees and supplemental credentials, particularly those associated with iSchools. Here, we look at various combinations of formalized programs, degrees and certificates, academic levels (undergraduate versus graduate), and the parts of the university that host DH curricula as well as their collaborators within the university. These official structures underpin all types of DH education for students in a university. Degrees usually include the bachelors major at the undergraduate level, and the masters or doctoral at the graduate level. Supplemental credentials - official acknowledgments on transcripts earned through the completion of a small program of coursework that is separate from the main degree - include minors at the undergraduate level and certificates at the graduate level. Our research developed out of our work on the iSchools Digital Humanities Curriculum Committee (iDHCC), an official panel of international teacher-researchers convened by the iSchools Organization to study DH curricula in and beyond iSchools. Our methods involve the examination of university websites, the querying of an online catalog of European DH education, and a questionnaire developed by the iDHCC and targeted at iSchools. These data were collected between February 2019 and October 2020. In this paper, we first review prior research on DH as an educational field, including a brief terminological review, and introduce the official iSchool classification. Next, we describe the methods used for data collection and analysis. Finally, we present and discuss our results and their potential implications for how iSchools should engage with DH educational programs at their universities. 


\section{Background}

\subsection{Digital humanities}

Digital humanities as a distinct academic field takes on fluid forms and definitions. For example, a volume entitled "Defining Digital Humanities" (Terras et al., 2013) highlights the diversity of topics covered in conference talks, essays, and blog posts about this subdiscipline and its activities. Descending from the field of Humanities Computing, whose origins reach back to the first computers of the late 1940s, the term "Digital Humanities" emerged in the early 2000s to differentiate higher-level research from basic digitization (Busa, 1980; Vanhoutte, 2013; Nyhan \& Flinn, 2016). The Oxford English Dictionary ("Digital humanities," 2020) defines DH as "an academic field concerned with the application of computational tools and methods to traditional humanities disciplines such as literature, history, and philosophy." Here, we utilize a broad definition of DH as an area of scholarly activity at the intersection of the humanities and computation, while also foregrounding the applications of digital tools and methods. By producing and deploying new software and techniques, DH opens novel approaches to teaching and research while simultaneously examining and critiquing how these innovations impact various aspects of cultural heritage and digital culture (Berry, 2012; Liu, 2013). Thus, DH both employs information technologies in the pursuit of the humanities, and subjects technology to humanistic interrogation.

More concrete definitions for DH often rely on illustrative examples in specific domains to demonstrate the wide variety of topics that fall under this heading. In this vein, we can point to how $\mathrm{DH}$ involves the digitization of archaeological objects and the establishment of related infrastructures to curate online collections and share information about objects across institutions (Smith et al., 2014; Cobb et al., 2019). This work can enable data mining on web archives or social media datasets, relying on a process of knowledge representation that spans acquiring, encoding, organizing, presenting, and linking data (Beck \& Neylon, 2012; Buccellati \& Kansa, 2016). DH also engages with the design of user interfaces for interactive access to and digital publication of data, underpinning the critical reflexive dimensions of digital transformation in a wide range of contexts. In fields like archaeology, DH methods target both digitized and born-digital materials, including text, multimedia, and 3D representations of physical objects and spaces (Roosevelt et al., 2015). DH approaches thus unite traditional humanities disciplines (archaeology, history, philosophy, linguistics, literature, art, music, and cultural studies) with computing tools (hypertext/media, data visualization, information retrieval, statistics, 3D modeling, data/text mining, digital mapping, and spatial analysis). In these intersections we see DH scholars not only using computational methods to answer traditional research questions, but also developing new questions that can be addressed with pioneering approaches that are enabled by this digital transformation of knowledge creation (Kansa \& Kansa, 2021).

Internationally, DH has developed its own character as a distinct academic field, which includes specific publications, education programs, job opportunities, organizations, and conferences. Several textbooks now cover DH and journals in the field 
include Digital Humanities Quarterly (DHQ), DHCommons, Digital Scholarship in the Humanities (DSH), and the Journal of Digital Humanities (JDH), to name a few. The number of DH programs at the bachelors, masters, and doctoral levels has grown steadily over the last few decades, especially since 2008 , as will be described below. The Alliance of Digital Humanities Organizations (ADHO), established in 2005 , acts as a key international association supporting DH research and teaching. It advises member associations around the world, including the European Association for Digital Humanities (EADH), which has overseen an annual DH conference since 2006. Particular regions of Europe also maintain local associations under EADH, such as Digital Humanities in Nordic Countries (DHN), which has organized annual conferences since 2016. Another constituent organization of ADHO is centerNet, an online international network formed in 2007 to link DH centers across the world. The centerNet now includes 200 centers at universities like Stanford, the University of Pennsylvania, Brown, the University of North Carolina at Chapel Hill, and Oxford (https://dhcenternet.org/). A Pan-European infrastructure for arts and humanities scholars called DARIAH (Digital Research Infrastructure for the Arts and Humanities) has facilitated collaborative DH projects since 2006. Two of the main DH organizations in North American are the Humanities, Arts, Science, and Technology Alliance and Collaboratory (HASTAC) and the Association for Computers and the Humanities (ACH), which is part of ADHO.

\section{2. iSchools}

The field of information studies (iField) investigates how humans interact with digital information and the resultant impacts on society. Formal programs in the iField have developed gradually over time and are associated with other academic disciplines such as computer science, business, and especially library science (Bartlett $\&$ Dalkir, 2020). The origins of the iSchools Organization are often traced to a small set of US universities with library or information science programs that began communicating with each other in the late 1980s (Larsen, 2008; Dillon, 2012). These programs began conceiving of an iField that built upon the traditional roles libraries played in the organization, preservation, and sharing of knowledge. Over time, additional universities joined the trend towards establishing iField programs. The first decade of the internet, beginning around 1995, witnessed a widespread recognition of the potential of digital communications to transform the conventional functions of libraries and other information brokers. This shift in thought provided the impetus for several schools of information to join together in an official interuniversity and international organization. Thus, in 2005 the iSchools Organization was officially established to enhance communication among iField programs at many universities.

Among the goals of the iSchools Organization are communicating the purpose and value of the iField to university administrators and others, preparing students for contributing to a society where digital information is exploding exponentially each year, and enhancing cross-university research (Larsen, 2008). To facilitate this 
latter topic especially, the Organization also began the iConference in 2005, an annual forum for people to share work and develop networks. The iSchools Organization has grown to include over 100 schools from around the world, and the iConference has become a major academic event.

The members of the iSchools Organization share "a fundamental interest in the relationships between information, people, and technology" (iSchools Organization, 2020). Information is central to today's society and, by extension, to human life. Thus, a connection between iField and humanities programs is a natural space for shared advancements. One noteworthy historical connection between DH and iSchools centers on Dr. John Unsworth, one of the coeditors of the 2004 book A Companion to Digital Humanities that popularized the term DH. Unsworth was at that time the Dean of the Graduate School of Library and Information Science at the University of Illinois at Urbana-Champaign, a prominent North American iSchool (Schreibman et al., 2004). He would later chair the iSchools leadership board from 2008-2010. Another demonstration of the connection between these academic disciplines comes from Weingart's 2016 investigation of the disciplinary breakdown of submissions to the 2017 annual ADHO-DH conference - the iField library and information science ranked third in popularity out of 34 topics.

The iField programs cover a wide range of topics and already offer a variety of degrees and supplemental credentials. "Degree programs at iSchools include course offerings in areas such as information architecture, design, policy, and economics; knowledge management, user experience design, and usability; preservation and conservation; librarianship and library administration; the sociology of information; and human-computer interaction and computer science" (iSchools Organization, 2020). We believe that digital humanities naturally fits into this topic list, and we hope through our research to show some approaches for making DH a regular part of iSchools education.

\section{Methods}

\subsection{Purpose and aims}

The purpose of this study is to provide an overview of possible implementations of DH education as an interdisciplinary field in any university, especially within iSchools or iField and related departments. Specifically, this study intends to describe various models for $\mathrm{DH}$ education that lead to degrees and supplemental credentials in order to inform university decision-making. In our conclusion, we make several recommendations for how iSchools could better engage with DH. The DH programs outlined here are based on our research of existing examples from worldwide universities, particularly within iSchools. Our work began under the auspices of the iSchools Digital Humanities Curriculum Committee (iDHCC), established in February 2019 for a two-year review of what DH education could entail within an iSchool.

DH programs could range from the offering of a few individual courses to compre- 
hensive degree programs, and everything in between (Sula et al., 2017). DH usually also involves a research component that might engage students directly in innovative work. Universities can offer DH degrees, supplemental credentials, and courses at multiple tiers or levels - from undergraduate majors, to post-graduate certificates, and masters and doctoral degrees. DH might be the focus of a primary degree, like a bachelors or masters, or it may be the subject of a supplemental credential like an undergraduate minor or graduate certificate. We are also interested in tracing which administrative unit officially hosts a DH credential within the university whether that be within the iSchool, another department, or a centralized structure at the university-wide level. Regardless of the primary or shared hosting of these official programs, interdisciplinary undertakings always engage collaborators across the university, so we also trace these. We organize and summarize an overview of existing programs by collecting data about $\mathrm{DH}$ at universities and iSchools worldwide and then make recommendations for iSchools based on these observations.

\subsection{Data collection}

To identify DH credentials at universities across the world, we approached data collection from several directions. First, the iDHCC undertook an initial manual ad hoc survey of websites from universities all over the world to locate existing DH programs both within and beyond iSchools. Second, we used the CLARIN-DARIAH online registry to gain a broad view of DH programs at European universities - again both within and beyond iSchools. Third, the iDHCC also initiated a targeted survey with an online questionnaire to gather perspectives on DH from iSchools themselves, across the globe. Fourth, we conducted a comprehensive survey of websites from North American iSchools to search for DH-related content. Here, we provide a detailed overview of each of these datasets and a discussion of their limitations.

\subsubsection{Website surveys}

Universities publicize their DH programs through their websites - targeting perhaps mainly their own current and prospective students, but also reaching many potential audiences. These websites provided us with details of the structure of each DH program, thus making them a rich source of data. However, manual time and effort were required to interpret and collate data as each website presents relevant information in a different way, sometimes with different terminology. The iDHCC conducted initial data collection from websites in March 2019, investigating universities on all populated continents. Committee members recorded DH programs within both iSchools and other units in universities, including at institutions that lack iSchools. Each committee member primarily cataloged programs and regions they were already familiar with, so this was an ad hoc survey.

Although we prefer comprehensiveness in our study, several factors led to incomplete data collection. As an unfunded project, resources were limited. This manual website survey was done voluntarily, with committee members adding information as 
they had time in their already overwhelmed schedules. Additionally, many worldwide university websites lack information in languages known to iDHCC members. Thus, the goal for the manual ad hoc survey was not comprehensiveness, but rather just to get a general sense of the range of types of DH education that already exist. Although not ideal for our study here, we agree that getting a general sense of the available options is important. With our limited resources, we attempted to fill in the gaps of this initial ad hoc survey with the following data collection efforts.

\subsubsection{Online DH course registry}

We supplemented the initial website survey dataset by examining the educational offerings listed in the CLARIN-DARIAH registry (https://dhcr.clarin-dariah.eu/). CLARIN, which stands for "Common Language Resources and Technology Infrastructure" and DARIAH, introduced above, are both European Research Infrastructure Consortiums (ERIC). CLARIN teamed together with DARIAH to create a registry that curates information about DH courses across Europe, with some coverage beyond. This source also has data challenges. Although it is the only comprehensive online catalog we found, it mostly focuses on European educational offerings. Furthermore, while this registry lists "DH courses," the interpretation of this term is quite broad - and may include individual classes or entire programs. Several programs closely related to DH are also listed, such as computational linguistics, media, digital culture, and artificial intelligence. We filtered the results based on an explicit mention of "digital humanities," "computational humanities," "humanistic informatics," and closely related terms in course titles. Although this data source provides uneven detail on the individual programs, its wide reach and ease-of-use made this an important part of our analysis at a high level.

\subsubsection{Online questionnaire survey}

The iDHCC aimed to document DH activities at iSchools worldwide, in order to a) help expose planned and existing DH education programs at iSchools and b) encourage other iSchools to consider implementing DH programs. The committee therefore developed a brief online questionnaire to collect self-reported details from individual iSchools. The requested information included a DH program title, establishment year, the department or unit of the university responsible for the program, a link to the program webpage, a contact person, the types of credentials or degrees offered, specializations within $\mathrm{DH}$, and collaborations with other parts of the university (see Appendix 1). Two separate forms gathered information about existing programs versus programs in the planning stages. The Sungkyunkwan University Data Lab administered the survey, which was created in November 2019 and pilot tested by several iDHCC members who entered information about their home iSchools.

The iDHCC emailed the survey to the heads of iSchools on January 9, 2020. Initial response rates were somewhat lackluster, so between May and October of 2020, we carefully targeted a new batch of individual emails at colleagues known to engage with DH at each iSchool. These emails tended to be sent out by iDHCC members 
who represented the target region. Also, based on the initial data collected, in June 2020 the committee decided to add the second form to allow iSchools to describe DH programs still in the planning stages. The uneven response rate, the varied details in each response, and the fact that multiple responses documented DH programs at their university but not within their iSchool, all make this a problematic dataset. Nonetheless, we have good targeted details for specific iSchool programs.

\subsubsection{North american iSchool website survey}

Noting the limitations of the other data collection efforts, particularly in terms of their lack of comprehensiveness, and our own time constraints, we decided to undertake one comprehensive survey of websites of iSchools in a single region. We chose the North American region because of its deep history in the iSchools Organization and our own familiarity with the region. We searched all university websites in North America with iSchools to look for any DH-related topics. Of course, our data collection here was limited to the information universities have decided to publicly share. As we emphasize in our conclusion below, we hope others will build on our work by gathering additional comprehensive datasets about other regions.

The end result of bringing together all these public website-based data collection efforts - the initial manual ad hoc survey, the online registry and questionnaire, and the North American survey - is our current study, which can only provide a picture of worldwide DH education and degrees that is incomplete and rough but also, we believe, useful and timely.

\section{Results}

\subsection{General digital humanities education and degrees}

First, we want to provide a general glimpse of what DH education and degrees look like at universities within any department or division. Through the manual website survey, the iDHCC cataloged 31 Asian and Australian DH programs at 15 universities, 44 North American DH programs at 39 universities, and 48 European DH education offerings (see Appendix 2 for a detailed catalog). Direct comparisons of these programs across continents are hindered by differences in terminology, local preferences for what information to put on websites, and variance in the ad hoc methods used by individual iDHCC members to select universities in each region.

Among the data collected from university websites of 9 countries in Asia and Australia, we found 18 programs at the bachelors level, 11 at the masters level, and 2 at the doctoral level. Among our sample, only universities in Japan, Australia, and Singapore indicated that they offer multiple DH programs at different degree levels. At the bachelors level, 6 programs offer a full major, 9 a minor, and 3 a specialization, certificate, or an honors degree. At the masters level, 5 programs offer a full Masters of Arts (MA) or Masters of Science (MS), and the remaining 6 programs offer a 
certificate or something similar, such as a minor or a diploma of arts. Two programs, in Japan and in Australia, offer interdisciplinary doctorates in DH. Among all the degree programs in Asia and Australia, $3 \mathrm{DH}$ programs have iSchool participation, but the rest of the programs are not part of an iSchool.

In our exploration of North America, we identified 3 programs in Mexico, 6 in Canada, and 35 in the United States. In 4 cases, the university offers multiple programs - usually one at the graduate and one at the undergraduate level. Two out of every 3 (29 of 44) programs grant credentials at the graduate level. The most common degree is a certificate offered at the graduate level (20) - or the somewhat similar specialization or concentration (2). The next most common option is the minor at the undergraduate level (7), with similar programs also called an undergraduate concentration, specialization, or certificate (5). We also found 7 masters degrees and 3 bachelors degrees in $\mathrm{DH}$. Some of the DH programs listed here do have connections to iSchools - either they are hosted by the iSchool, or iSchool courses and faculty engage with a DH program hosted in another department.

The initial search of websites by the iDHCC identified $48 \mathrm{DH}$ educational programs in Europe, distributed across 17 countries: Austria, Belgium, Estonia, Finland, France, Germany, Ireland, Israel, Italy, Latvia, the Netherlands, Russia, Slovenia, Spain, Sweden, Switzerland, and the United Kingdom. The majority of these programs engage students at the masters level. Of these, most are MA (23), a few are MS (4), and some are Masters of Philosophy (MPhil) (2). Additionally, there are 4 masters minors and 4 masters specializations or similar supplemental credentials. At the undergraduate level, we found 7 programs, of which 5 provide a Bachelors of Arts (BA), 1 a Bachelors of Science (BS), and there was 1 undergraduate minor program. Finally, the European universities offer a handful of doctoral degrees (3), as well as 1 summer school in DH.

To update these initial findings, we leveraged data from the CLARIN-DARIAH registry that we downloaded in September 2020. This registry helped us to update the picture in Europe since it focuses mostly on this region, with only four countries outside of Europe in the dataset. Taking into account all educational offerings considered to be DH by the people who originally input them into the registry, including even those programs not explicitly labeled as digital humanities, we counted the following number of each type of program: bachelors programs (83), masters programs (162), doctoral programs (16), modules (25), individual courses (129), summer school (12), and continuing education (2). Thus, besides individual courses and modules, the majority of programs are masters degrees, followed by bachelors degrees, and finally doctoral degrees.

The CLARIN-DARIAH registry also enabled us to look more closely at the disciplines represented by these different DH programs. Here again we filtered the data based on the programs as described above (with DH or closely related areas explicitly mentioned in the title). Each person who entered a program also had the option of registering multiple discipline categories for it. We counted the following number of each disciplinary label: theory and methodology of DH (148), arts and cultural studies 
(126), linguistics and language studies (118), computer science (107), history (103), and literary and philological studies (99). The next most common set of disciplinary labels are library and information science (55), media and communication studies (51), social sciences (42), archaeology (39), philosophy (17), ethnology (16), and musicology (15). Less well-represented disciplinary labels include religious studies (10), gender studies (9), cognitive science (8), legal studies (8), and an "other" category (22).

The combination of this website survey and the use of the online catalog provides the opportunity to make several very general and high-level observations regarding the implementation of DH education across the globe. These frame our discussion of DH within iSchools in the following section. First, there are some striking differences among the different geographical areas we studied. Asia, Australia, and North America tend to focus more on supplemental credentials rather than terminal DH degrees. The reverse is true in Europe, where most programs offer a masters or a bachelors degree. Second is the emphasis on graduate-level education in North America and Europe, whereas undergraduate degrees and credentials are relatively better represented in Asia and Australia. We need to highlight again, however, that this was not a comprehensive survey as we did not review all DH programs in the world, though we feel we do have enough data to reflect on general underlying trends.

\subsection{Digital humanities related to iSchools}

Moving from this general overview of global DH programs and degrees situated in any part of a university, we next turn our attention to how DH education relates to iSchools. Our initial source of data on DH in iSchools comes from the abovementioned online questionnaire sent out by the iDHCC to every iSchool. These results were then supplemented by our own detailed examination of all the iSchool websites in North America, undertaken during September and October of 2020.

\subsubsection{Online questionnaire survey}

Out of 117 total iSchools, representatives from 36 iSchools filled out one of the two forms in the online questionnaire prior to October 15, 2020 (see Appendix 1 for the questionnaires). One of the forms was targeted at existing DH engagement $(n=32)$ while the other requested information about planned DH programs $(n=4)$. The 4 iSchools in the planning stage for DH programs include 2 in China (Shanghai University and Wuhan University), 1 in South Korea (Sungkyunkwan University), and 1 in the United States (Kent State University). Several iSchools in Europe wrote by email to inform us that they neither currently have a DH program nor plan to start one in the foreseeable future $(n=6)$, or are too early in the planning stages to contribute to the survey $(n=2)$. Thus, the response rate among all iSchools was about $37.6 \%$, with some sort of response from almost two-fifths (44 out of 117). We also postulate that some iSchools did not fill in the online questionnaire or correspond with us because they have no existing or planned DH. For an inventory of the 32 iSchools 
Table 1

Inventory of the 32 iSchools that completed the iDHCC online questionnaire indicating current engagement in DH education in some form. Universities are organized according to iSchool regions and quantified relative to the total number of iSchool members in that region as of October 2020. For region definitions, see iSchools Organization (2020)

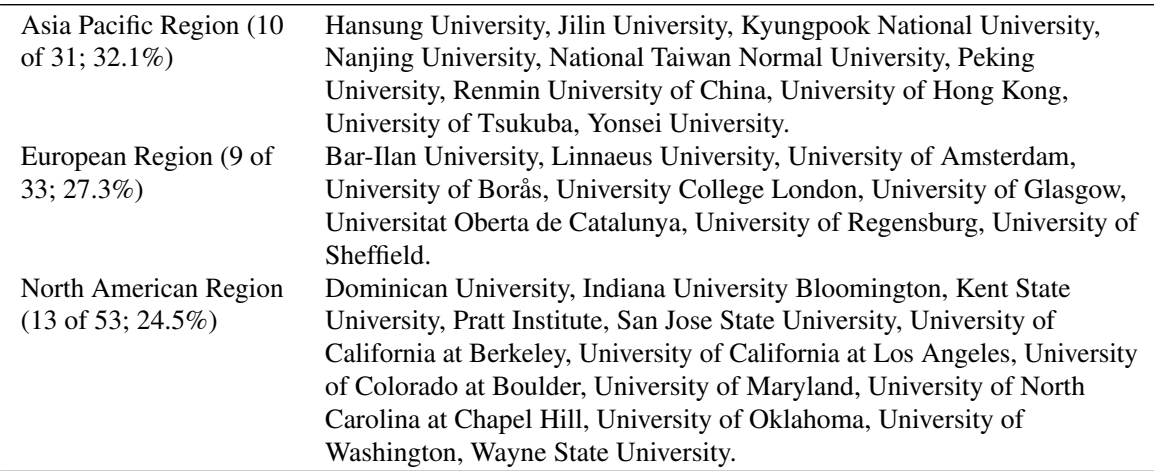

that reported some type of existing engagement with $\mathrm{DH}$ in the online questionnaire, please see Table 1 below. The ways each iSchool engaged with DH varied widely, including: having faculty doing DH research, offering DH courses, collaborating with DH programs in another part of the university, or offering an iSchool degree or supplemental credential in $\mathrm{DH}$.

\subsubsection{Digital humanities credentials and programs}

Among the 32 iSchools that filled in the online questionnaire describing DH engagement, some reported the official degrees and credentials outlined in Table 2 below. In total, 18 iSchools replied 'yes' to the question about whether their program or university issues a degree or credential in DH. Although the online form asked separate questions regarding the names of the program and of the degree, the fields were open text rather than multiple choice, therefore we received a wide range of values. Sometimes the name of a university or specific unit within the institution was input in the field for the "name of program." Therefore, we combined the two questions - whether they had a DH program and whether they issued a degree in $\mathrm{DH}-$ in this analysis. Where possible, we tried to verify the information on a given website or to contact the person who entered the data.

\subsubsection{DH program start years}

The iSchool questionnaire participants were also asked to specify the year their DH program began. Figure 1 graphs the results of this question. The temporal pattern in the establishment of $\mathrm{DH}$ programs associated with iSchools follows the general trend of the development of the $\mathrm{DH}$ research field. Thus, the programs represented in our dataset began slowly in the 2000s and increased significantly in the 2010s. The earliest schools to introduce DH curricula were all in Europe - the University of 
Table 2

Digital Humanities credentials and other programs reported by the iSchools through the iDHCC online questionnaire about existing DH education (universities which offer more than one degree in DH are repeated)

\begin{tabular}{|c|c|c|}
\hline Level & $\begin{array}{l}\text { DH credential } \\
\text { or program }\end{array}$ & University (specific program) \\
\hline \multirow[t]{5}{*}{ Undergraduate } & Bachelors of Arts & Yonsei University (Digital Humanities) \\
\hline & Major & $\begin{array}{l}\text { Universitat Oberta de Catalunya (Digital Humanities) } \\
\text { University of Amsterdam (Cultural Information Studies) }\end{array}$ \\
\hline & Specialization & Hansung University (with Library and Information Science) \\
\hline & Minor & $\begin{array}{l}\text { University of California at Los Angeles (Digital Humanities) } \\
\text { University of California Berkeley (Digital Humanities) }\end{array}$ \\
\hline & Badge & $\begin{array}{l}\text { University of North Carolina at Chapel Hill (Digital Advancement } \\
\text { in Data Studies) }\end{array}$ \\
\hline \multirow{7}{*}{$\begin{array}{l}\text { Graduate- } \\
\text { Masters }\end{array}$} & Masters & Renmin University of China (Digital Humanities) \\
\hline & & $\begin{array}{l}\text { Nanjing University (Information Resources Management, Big } \\
\text { Data Analytics) }\end{array}$ \\
\hline & Masters of Arts & $\begin{array}{l}\text { University of Regensburg (Digital Humanities) } \\
\text { Bar-Ilan University (Digital Humanities) } \\
\text { Linnaeus University (Digital Humanities) } \\
\text { University of Glasgow (Digital Media and Information Studies) }\end{array}$ \\
\hline & $\begin{array}{l}\text { Masters of Arts and } \\
\text { Masters of Sciences }\end{array}$ & University College London (Digital Humanities) \\
\hline & Certificate & $\begin{array}{l}\text { Dominican University (with Information Management or Library } \\
\text { and Information Science) } \\
\text { Indiana University Bloomington (with Library Science or } \\
\text { Information Science, or in Digital Arts and Humanities) } \\
\text { University of California at Los Angeles (Digital Humanities) } \\
\text { University of Colorado at Boulder (Digital Humanities) } \\
\text { University of North Carolina at Chapel Hill (Digital Humanities) } \\
\text { University of Oklahoma (Digital Humanities) } \\
\text { Pratt Institute (Digital Humanities) } \\
\text { University of California Berkeley (Digital Humanities) }\end{array}$ \\
\hline & Pathway of Study & Kent State University (Digital Humanities) \\
\hline & Badge & $\begin{array}{l}\text { University of North Carolina at Chapel Hill (Digital Advancement } \\
\text { in Digital Pedagogy or Digital Project Management) }\end{array}$ \\
\hline $\begin{array}{l}\text { Graduate- } \\
\text { Doctoral }\end{array}$ & PhD Minor & Indiana University Bloomington (Digital Arts and Humanities) \\
\hline \multirow[t]{4}{*}{ Other } & Summer Institute & $\begin{array}{l}\text { University of Washington in partnership with the University of } \\
\text { Victoria (Digital Humanities) }\end{array}$ \\
\hline & Institute & $\begin{array}{l}\text { University of Maryland (Maryland Institute for Technology in the } \\
\text { Humanities) }\end{array}$ \\
\hline & $\begin{array}{l}\text { Individual DH } \\
\text { Courses }\end{array}$ & $\begin{array}{l}\text { Kent State University } \\
\text { Wayne State University (DH course in the History Department) } \\
\text { University of Tsukuba (DH course in the Masters in Informatics } \\
\text { Program) } \\
\text { San Jose State University }\end{array}$ \\
\hline & DH Integrated into & National Taiwan Normal University \\
\hline
\end{tabular}


Table 2, continued

\begin{tabular}{lll}
\hline Level & \multicolumn{1}{c}{$\begin{array}{c}\text { DH credential } \\
\text { or program }\end{array}$} & \multicolumn{1}{c}{ University (specific program) } \\
\hline Other & Existing Courses & $\begin{array}{l}\text { University of Hong Kong } \\
\text { University of Sheffield } \\
\text { University of Borås (in the specialization in Digital Library and } \\
\text { Information Services; classes open to DH program at University } \\
\end{array}$ \\
& of Gothenburg) \\
\cline { 2 - 3 } & Jilin University (Digital Humanities and Knowledge Service) \\
& Kyungpook National University (Glocal Cultural Contents \\
& Creative Genius Training) \\
& Peking University (Program in Digital Contents and Information \\
& Studies) \\
&
\end{tabular}

Glasgow (2001), the University of Amsterdam (2003), and the University of Borås (2008). Although these initiatives may not specifically reference "Digital Humanities" in the program or credential title, they all integrate DH into many courses (cf. Table 2 above). The first iSchool program that explicitly used the term "Digital Humanities" in its title was established in 2010 at University College London (UCL), followed in 2011 by the University of California at Los Angeles and the University of North Carolina at Chapel Hill, and in 2012 by the University of Washington. Most of the DH programs reported in our dataset were developed after 2014, and, as mentioned above, a handful are still in the planning stages so they are counted with 2020.

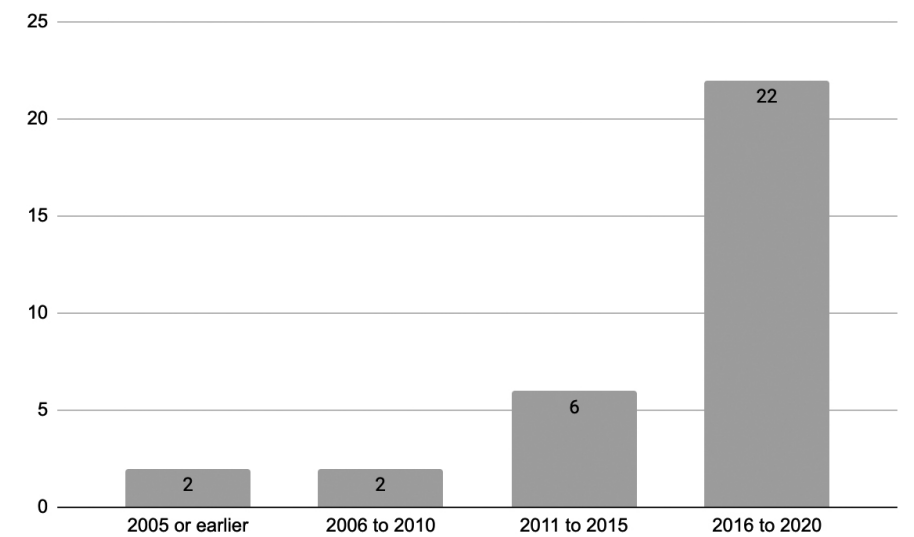

Fig. 1. Quantitative groupings of iSchool DH programs by year of program start, based on data reported in the iDHCC online questionnaire.

\subsubsection{Collaborations beyond the iSchool}

Several of the DH educational programs outlined by the iSchool representatives in the online questionnaire are not hosted by the iSchool itself. The online form asked each iSchool about their collaborative efforts with units in their university beyond 


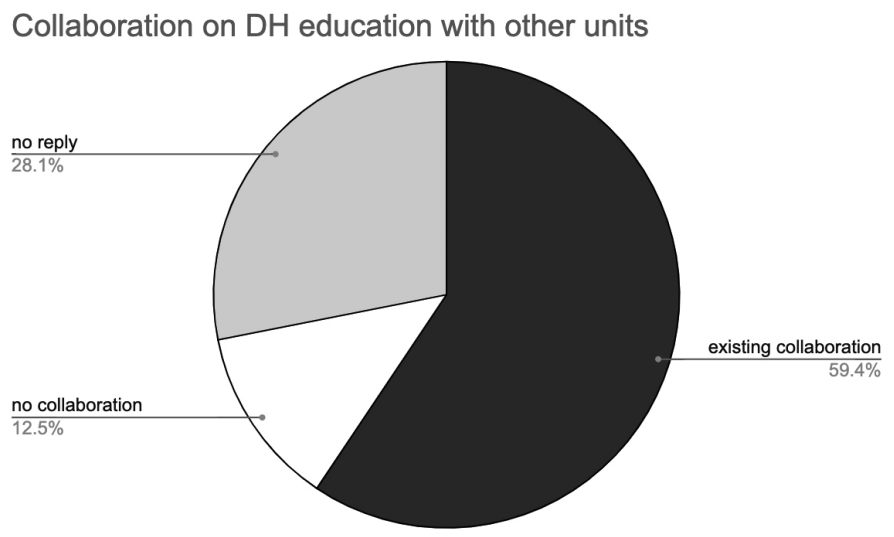

Fig. 2. Indication of collaboration reported by the iSchools through the iDHCC online questionnaire.

the iSchool. We can see from Fig. 2 that the majority of iSchools collaborate on DH education with other units (19 out of 32, or 59.4\%). A much smaller portion specifically indicated that they do not actively collaborate on DH education (4 out of 32 , or $12.5 \%$ ), though this is likely changing all the time. For example, Dominican wrote "not currently" in this field, implying the possibility of future partnerships. The remainder of the iSchools provided no reply (9 out of 32 , or $28.1 \%$ ) as this was not a required field.

In terms of the details for how these different intra-university divisions collaborate with each other, we observe a wide variety of relationships. On the one hand, the iSchool may provide or accept course credits towards a DH degree. On the other hand, there may be a centralized DH center, to which the iSchool contributes classes or other expertise. The centralized DH center may also involve the university library. In many cases DH degree programs are situated in a department or faculty external to the iSchool, so the iSchool may engage with those external programs. Finally, in several cases the DH credential is combined with another degree, such as a masters in history, which means that these degrees may be inside or outside of the iSchool.

\subsubsection{4 iSchools with $\mathrm{DH}$ in the planning stage}

Each of the 4 iSchools in advanced planning stages intends to create a program that explicitly mentions digital humanities in the title. Kent State University indicated that it will start a program without a terminal degree in 2021, whereas the rest will start programs in 2020 - with Sungkyunkwan and Wuhan planning to offer a degree, but not Shanghai. Rather than a standalone degree, Kent State intends to establish two choices for students to complement their masters programs - a pathway in digital humanities or a summer school in digital conservation. Sungkyunkwan aims to offer DH education at all three educational tiers, with a BA in digital humanities, an MA in digital humanities, and a $\mathrm{PhD}$ in digital humanities. Wuhan, however, plans to offer an MS in digital humanities. 
Two of the 4 iSchools in advanced stages of planning intend to officially engage with collaborators beyond their home iSchool. Sungkyunkwan is aiming for a broad audience by laying the groundwork for possible cross-university registration and virtual course sharing. They hope to support virtual and in-person student or faculty exchanges, including with the Sungkyunkwan College of Arts and Sciences' DH Lab and groups at other universities, like Kent State. The iSchool at Sungkyunkwan is creating an iCollege that will serve as the center for all interdisciplinary teaching and research on campus. All humanities majors will be encouraged to do a dual major in DH, while social science students will be encouraged to take a dual major in social informatics. At Kent State, the pathway in digital humanities will include several courses from the applied data science minor, which is being planned separately and will also be hosted by the iSchool.

\subsubsection{North american website survey}

As of October 2020, there were 51 iSchool members located in North America, covering the United States and Canada. In the Fall of 2020, we undertook a detailed manual survey of iSchool websites in order to find any information about DH (see Appendix 3 for details not listed in the tables here). The main result indicates that a relatively small percentage of iSchools directly offer their own DH credential, with only 8 of the 51 directly offering a DH credential (see Table 3 ). Five of these had also self-reported in the iDHCC survey - reflecting perhaps that those who chose to answer that questionnaire were in fact the only programs currently engaging in DH. Among the 8 with credentials, 6 iSchools offer their own supplemental graduate credential, most often described as a certificate but also referred to as a specialization or pathway. Additionally, the University of Oklahoma iSchool has a joint DH graduate certificate with administrative units outside the iSchool and the Indiana UniversityPurdue University Indianapolis iSchool offers a joint undergraduate minor with other units outside the iSchool.

Among the 51 North American universities that host iSchools, 32 of them had some sort of official DH program either in a central administrative unit like the library or in another academic division, usually a humanities department (63\%, or almost two-thirds). About one-third of those $\mathrm{DH}$ programs engaged the iSchool in some publicly apparent way (11), of which 2 of these also had an official DH program within the iSchool (the University of Oklahoma and the University of Texas at Austin, mentioned above). We found that at least 9 iSchools offer dual degrees with humanities programs, and so these may have some affinity with DH (see Table 4). For example, several iSchools offer a joint masters degree between history and iFields like library or information sciences. It may be the case that some of these joint programs existed prior to the rise in popularity of the term "digital humanities," so that if they were to be developed today they might promote themselves as DH. Interestingly, most of these universities have another unit at the university that explicitly conducts research in $\mathrm{DH}$ or offers degrees in $\mathrm{DH}$. 


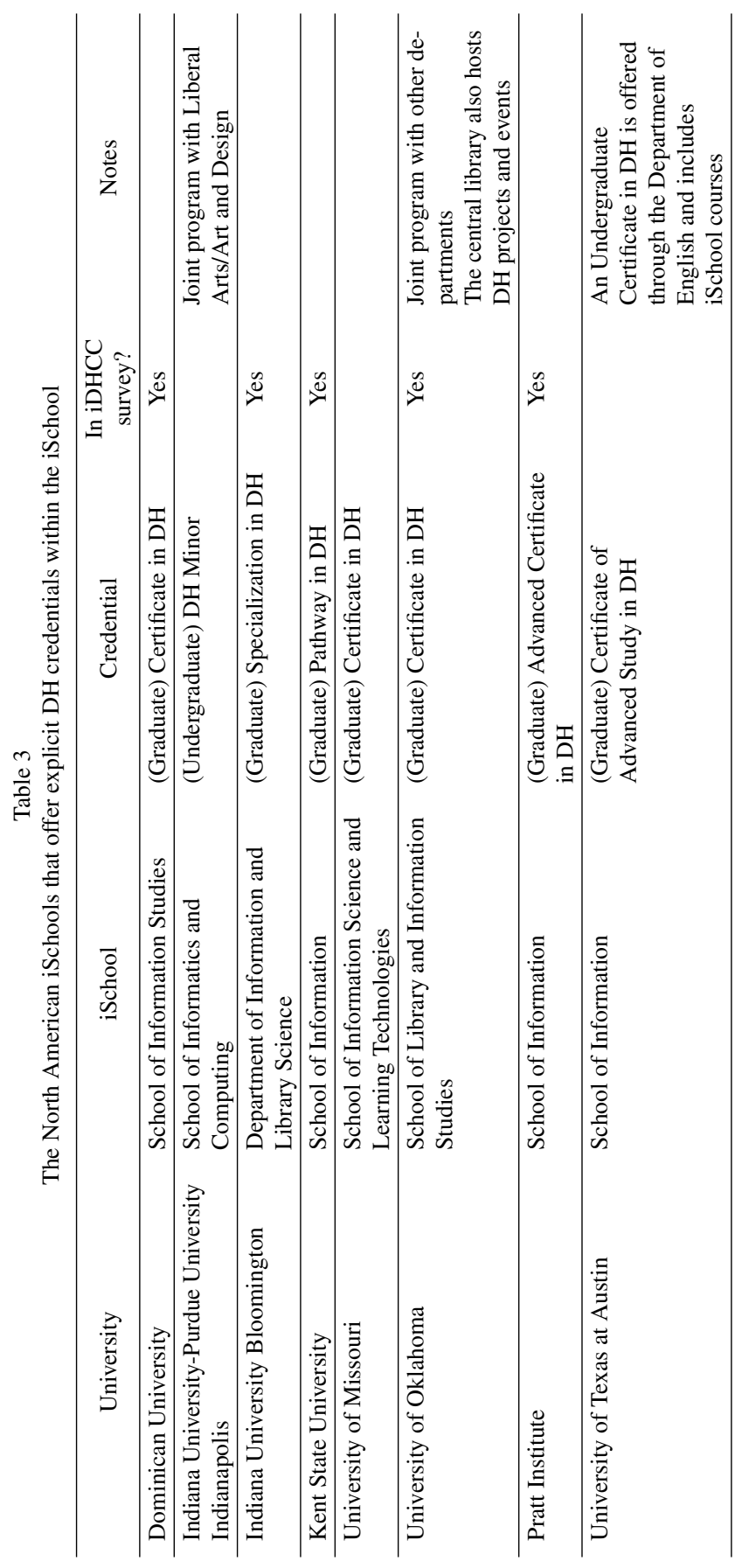




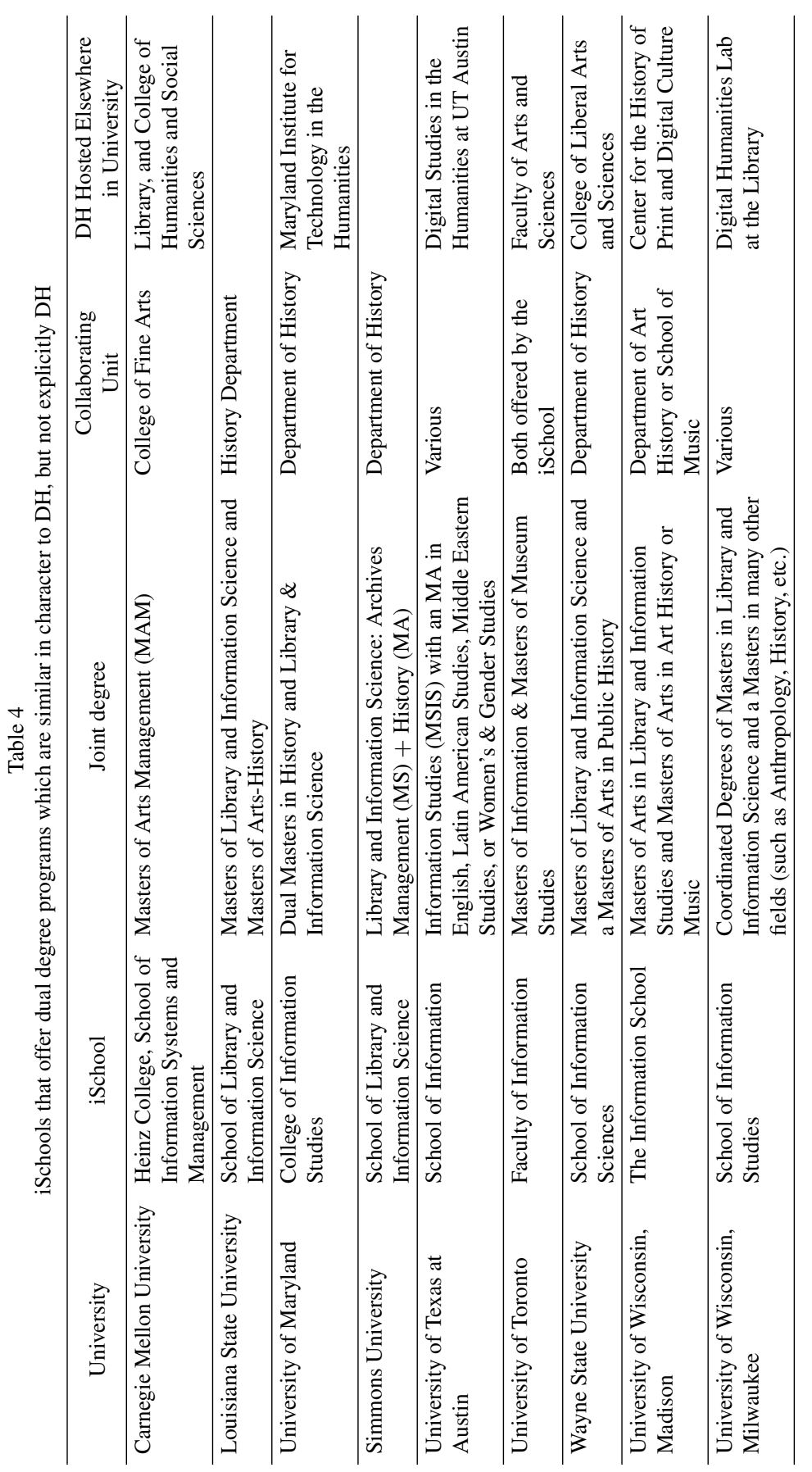


Much more challenging to ascertain with precision is how engaged individual faculty members in each North American iSchool are in DH. We were able to gather information that indicates that at least 23 iSchools have faculty members involved in DH in some way - whether through research or by teaching individual DH courses. There were at least 14 iSchools that listed courses that were specifically branded as $\mathrm{DH}$, many of these in the iSchools that explicitly offer a DH credential as listed above.

Thus overall, we see the same patterns as outlined in the prior section about the iDHCC online questionnaire. DH is not usually offered in an iSchool, instead being offered by another administrative unit at the university. Several iSchools offer dual degree programs, which may have existed since before DH became popular. In general, iSchools are more likely to have individual faculty who engage in some way with DH rather than the iSchool implementing any official program. The other observation is that among the few iSchools that offer a DH degree, none of them are terminal degrees, rather they are all supplemental credentials, which was the preference we outlined before for North American DH.

\section{Discussion}

These results indicate significant room for growth within iSchools for DH education. Several models for how iSchools can implement DH degrees and supplemental credentials can be found in examples already put into practice by both iSchools and other academic units in universities around the world. Now is the time for iSchools to take up this challenge and embrace a more active role in establishing DH education at their universities. This type of interdisciplinary engagement may offer iSchools a new way to have an impact and increase their exposure. In an earlier issue of this journal, Marcella and Oppenheim (2020) present the challenges for the future sustainability of library and information science programs in the UK, part of the iField often covered by iSchools. Yet, they also note that: "The current information environment is full of problems: information overload, fake news, media control, abuse of social media, preservation challenges, etc. There is precedent in LIS for addressing some of these in the past" (Marcella \& Oppenheim, 2020: 434). If iField programs have the potential to contribute to humanistic solutions for society but are also facing the requirement to justify their existence, then we believe DH presents an ideal area of expansion for iSchools and other iField departments (in agreement with Robinson et al., 2015).

This paper aims to propose potential roles for iSchools in establishing and participating in programs that offer DH degrees and supplemental credentials. In this section, we summarize what we have observed about DH education around the world. Then we use this information to make recommendations for how iSchools can engage with these degrees and credentials. We hope that this discussion will support iSchools to take on a leadership role in establishing DH programs at their universities.

\subsection{DH education degrees and supplemental credentials}

We observe a variety of ways universities implement DH degrees and credentials 
around the world. These differ based on the level of the degree and whether the university offers multiple degree levels simultaneously, whether it is a terminal degree or a supplemental credential, the type and name of the credential, the administrative unit offering the degree or credential, and the role of the iSchool in each program.

The degree and credential options span from a full undergraduate bachelors degree or an undergraduate supplement like a minor, to a full graduate masters degree or a masters supplement like a certificate, to a doctoral degree. We found that only a small number of universities offer degrees or credentials at multiple levels at the same time - in these rare cases, usually both an undergraduate degree or supplemental credential and a parallel masters degree or supplemental credential are offered simultaneously. Almost no universities grant both a full degree and a supplemental credential at the same level - for example, they will offer a full masters or a graduate certificate, but not both. Very few universities offer a DH degree at the doctoral level. Finally, there are various ad hoc implementations of DH education, including summer schools and continuing education programs. These may provide brief opportunities for students to begin to familiarize themselves with the field.

We find it interesting that DH is often conferred as a supplemental credential rather than a terminal degree. This seems to imply that the subject has not yet fully developed its own identity and ability to stand at a level equivalent to more traditional subjects. Similarly, the scarcity of doctoral degree programs may indicate a lack of confidence in the potential of pure DH research. Stand-alone digital humanities departments are rare to nonexistent (we did not find any in our search). Given the relatively recent formation of the iField itself and its position at an interdisciplinary boundary, iSchools could potentially lend their knowledge about academic organizations and procedures to help guide the further institutional development of the DH field. Perhaps DH can follow the direction of the iField to develop administrative units at universities for DH that are similar to iSchools, which bring together faculty members for shared efforts in research and teaching.

We can also look more closely at the purpose of programs that do offer a full masters degree. The intention of such a degree is for the student to build expertise and specialization in DH based on a foundation of prior university education. Applicants should hold a bachelors degree in any humanities field or related discipline such as social sciences. Team-building is key to DH, therefore teams of students and, later, professionals and researchers, who have both interdisciplinary backgrounds and DH training are advantageous for tackling complex problems. However, given the diverse backgrounds of masters students, these programs must first provide introductory courses in DH and its methodologies, rather than building on such courses taken by students at the undergraduate level. In this respect, a DH masters is similar to a masters in an iField discipline like library and information science, which may accept students with a bachelors degree in any area of specialization. These types of programs then teach the theories and methodologies of library and information science from the beginning without assuming prior knowledge.

As we have seen, there are interesting regional differences for what degrees or sup- 
plemental credentials are made available. On the one hand, European universities offer more terminal degrees in $\mathrm{DH}$, especially masters and bachelors degrees. Universities in the remainder of the world have arranged their DH education primarily around supplemental credentials, like the undergraduate minor or the graduate certificate. On the other hand, DH education tends to take place at the graduate level in Europe and North America versus the undergraduate level in other places in the world. There seems to be an expectation in these regions that students will first have either humanities domain knowledge or technical skills from an undergraduate degree before they begin studying DH. Future research could investigate the underlying cultural and contextual aspects to the decision making that has led to these divergent trends. Although we would recommend eventual standardization across the globe, at this point local iSchool leaders should take into consideration these regional preferences when building DH programs.

\subsection{Proposals for iSchools}

Based on the results of our data analysis, we can now make some preliminary recommendations specifically for iSchools. At a high level, we strongly believe that iSchools should engage more actively with the general conversations about DH happening in universities today. The iField holds both deep expertise in the implications of technology for human society and has the technical skills to support analytical DH research. At the same time, iSchools could benefit from this relationship to help overcome the challenges they face in communicating to other parts of the university about what they do. Making these connections could help to enhance partnerships with humanities colleagues and attract new students into iSchool programs and courses. Yet, few iSchools currently grant DH degrees or supplemental credentials - though we see positive signs in the development of interconnections between iSchools and humanities or other departments.

\subsubsection{Degrees and supplemental credentials}

As mentioned above, 4 iSchools reported in the online questionnaire that they are planning to offer their own DH programs, thus highlighting the potential for iSchools to implement the degrees and supplemental credentials we have documented here. Partnerships with humanities departments can be useful, but iSchools should take on a prominent leadership role in implementing DH either as part of these partnerships or on their own. The specific degrees or credentials that an iSchool should establish will depend to some extent on geography, as mentioned above. Given that many iSchools only focus on graduate-level education, our primary recommendation is to offer a graduate certificate or a full masters degree. If, however, an iSchool tends to work at the undergraduate level, then a full bachelors or a minor in $\mathrm{DH}$ could be added to the curriculum. We do not see much difference between a masters of science (MS), a masters of arts (MA), or masters of philosophy (MPhil) - or between a bachelors of science (BS) or a bachelors of arts (BA) - and we wonder how the differentiation 
would be justified in each case. Perhaps an MS or BS would be preferred to highlight the technical nature of the degree as the arts aspect of the degree would already be captured by the "humanities" in DH. We cannot recommend that any university offer a doctoral degree at this time as there may be complications for placing students who earn such a degree, given the lack of DH departments. We also do not recommend ad hoc educational models such as summer schools or continuing education as they cannot offer the depth of experience needed to master the skills in this field. Further recommendations could be guided by future research and evaluation of the relative success of different degree programs.

\subsubsection{Partnerships}

At a high level, a university will benefit the most when a wide variety of strengths are leveraged and combined from all sectors of the community. Since iSchools have significant experience and knowledge to offer to DH programs, they can valuably boost any DH effort. The iDHCC survey demonstrated that several iSchools already have existing collaborations with external units. These programs interconnect in a wide variety of ways - from cross-listing courses, to engaging in advanced research together, and supporting shared degrees and credentials. Partnerships can be valuable, but we should emphasize that iSchools should avoid serving in a subordinate capacity within official interdisciplinary relationships. Collaborations should be seen as an opportunity for iSchools to receive important university-wide recognition for their work. In particular, one area where we see iSchools adding a missing component to DH programs is in the support of a broad implementation of DH while simultaneously underpinning research with deep technical knowledge. When a DH program is hosted by a specific humanities department - such as English or linguistics - it often becomes very focused on a specific set of questions and methods to the exclusion of other important DH topics. An iSchool could act as a facilitator of collaboration across many different subdisciplines and support technical work on a wide range of data types. For example, one could foresee a role for an iSchool in bringing together text-based researchers with those working on material culture - thus bridging the divides between the different software, workflows, data types, and research questions inherent to each area of study.

Among the North American universities with iSchools, the part of the university most engaged with DH tends not to be the iSchool itself, but rather an administrative unit in another area. At these universities, humanities departments or centralized units like libraries, are usually the leaders in implementing DH education. Future research could compare this structural trend to those in other geographical regions of the world. Cases where DH has already been established, but iSchools are not yet a central player, show two potential avenues for engagement between iSchools and $\mathrm{DH}$ - first through the dual degrees we documented at some of these iSchools and second through leveraging the traditional role iSchools play in training librarians (Sula, 2013). Dual degree programs often take the form of a masters degree in a domain such as history together with a masters degree in an iField such as information 
science. The main downside to such dual degrees is, of course, the costs for the students - both temporal and financial. Furthermore, these programs may lack true integration of ideas. Despite these drawbacks, however, they may still serve as good stepping-stones for the future development of more integrated degrees. The prospect for iSchools to help train specialists to work as DH professionals in libraries is quite appealing, especially since iSchool degrees often qualify students for job placement in libraries.

As members of iSchools, we believe that iSchools have a lot to offer to DH research and teaching, particularly given the traditional focus on human-computer interactions. Therefore, we hope that iSchools will continue to actively seek out potential partnerships with humanities departments and other units at their universities.

\subsubsection{An eye towards employability}

As iSchools consider implementing new degrees and credentials, they also need to consider possible career paths for their graduates. There are several potential groups of students who might be attracted to undertake DH education in iSchools. For example, students with bachelors degrees in humanities may be interested in a masters degree with a strong focus on information technologies, recognizing this knowledge as highly desirable in the job market. Another potential audience may be GLAM (galleries, libraries, archives, and museums) professionals looking to update their technology and information skillsets. Elementary, middle, and high school teachers may also want to learn more about digital methods and digital transformations of society to help better prepare our children. Information technology professionals from many backgrounds - database administrators, web developers, robotics programmers, etc. - may be looking for a career change where they can bring their existing skills into humanities fields. Any of these audiences would already feel welcome in joining an iSchool program. Considering each of these potential DH student groups, there are some interesting prospects for students after they complete their degree. For example, a challenge facing the GLAM and cultural heritage sector is the lack of technologyliterate team members. Potential employees generally either know technology really well but find it hard to understand the application context, or vice versa (Billore \& Golub, 2017). Therefore, carefully curating both skillsets through a DH degree in an iSchool may raise the employability of people with humanities backgrounds and may provide a pathway into the humanities for people with technology backgrounds.

One may also foresee several new roles undertaken in existing jobs or even the creation of entirely new kinds of jobs. Obvious examples include the need for programmers, web developers, and project managers within DH centers or on DH projects; librarians who provide data management guidance, metadata expertise, or other digitization-related advice; school teachers who can integrate technologies into the classroom; and academics or researchers in the humanities or related fields. Examples of potential jobs found on the Digital Humanities Now website (https://digitalhumanitiesnow.org/category/news/job/) include DH project managers, DH librarians, DH center coordinators/directors, technical developers, tenure-track 
positions in DH, and DH post-docs. Hopefully, the unique blend of technology and humanities skills that an iSchool could impart during a DH degree program would make students competitive for such jobs.

\subsubsection{Terminology}

Perhaps the biggest challenge we found during our research was the wide range of terminology and definitions used by the different programs. This can make it difficult to equate specific degrees, tiers, or types of intra-university engagement across different universities and continents. The field of DH is continuously evolving these days, and we anticipate that it will not settle over the course of the next decade either. However, we also anticipate that more and more humanities scholars will take part in tasks that could be classified as DH. Digital methods are pervading every part of our lives, including our academic work. For the benefit of students, we recommend uniformity in the names of the degrees and credentials to follow mainstream trends, particularly so that potential employers will easily understand the qualifications of candidates. For example, many people outside academia may not know what a "pathway" means as part of a credential, but they may be familiar with the more common concept of a "graduate certificate." Therefore, to avoid a fragmented field, the most common terms should be used for naming DH degrees and credentials. For a supplemental credential at the graduate level, the term "graduate certificate" should be used instead of any of these terms: concentration, specialization, pathway, track, minor, diploma, and badge. At the undergraduate level, the very common term "minor" should be used for a supplemental credential in DH, and the following terms should be avoided: certificate, concentration, specialization, honors degree, badge. Although there may be an argument for some regional differentiation in these terms, in most cases these are standard across the world.

\section{Conclusion}

Similar to Senchyne (2016), we see DH as an opportunity for iField education to broaden its scope and more closely integrate with domain-specific knowledge fields. The combination of a wide range of humanities subjects with the focus of the iField on the relationships between humans and technologies makes iSchools an excellent home for Digital Humanities teaching. In summary, DH provides opportunities for iSchools to: 1) collaborate with other units on campus (e.g., humanities departments and $\mathrm{DH}$ centers); 2) collaborate across the iSchools Organization and plug in to the international dimension typical of DH scholarship; 3) lead DH efforts at their universities; 4) expose humanities students to iSchool research, teaching, and career opportunities; 5) develop courses focused on cultural and humanities data that may serve data science programs; 6) demonstrate the breadth and scope of iSchool research and teaching through DH (points taken from the iDHCC presentation of Walsh et al., 2019). 
Through our study, we have documented many examples that can inform decision making by iSchools that are looking to develop their own programs in $\mathrm{DH}$, or at least partner with other units in the university to offer DH. Programs in the iField like iSchools have always upheld a tradition of interdisciplinary activities across their research and teaching. We highly recommend that iSchools proactively aim to host $\mathrm{DH}$ degrees and supplemental credentials, while at the same time collaborating with other units at their universities. An iSchool that wishes to take the first steps in this process could begin with a supplemental degree at a single tier - either an undergraduate minor or a graduate certificate - before moving on to a full, terminal degree program. We also hope that other researchers will expand on our work by undertaking comprehensive surveys of DH programs at iSchools in other parts of the world.

\section{Acknowledgments}

The authors wish to thank the iDHCC team for the collaboration on exploring DH education, specifically: Sam Oh (Sungkyunkwan University, South Korea) [convener], John A. Walsh (Indiana University, USA), Marcia L. Zeng (Kent State University, USA) [co-chairs], Wayne de Fremery (Sogang University, South Korea), Ying-Hsang Liu (University of Southern Denmark, Denmark), Jeonghyun (Annie) Kim (University of North Texas, USA), Joseph Kiplangat (Moi University, Kenya), Simon Mahony, (University College London, UK), Chris Alen Sula (Pratt Institute, USA), Ted Underwood (University of Illinois, USA), Xiaoguang Wang (Wuhan University, China). Special thanks to Sunny Han of the Sungkyunkwan University Data Lab who administered the survey.

\section{Supplementary data}

The supplementary files are available to download from http://dx.doi.org/10.3233/ EFI-200452.

\section{References}

Alexander, B., \& Davis, R.F. (2012). Should liberal arts campuses do digital humanities? Process and products in the small college world. In Gold, M.K., (Ed.), Debates in the Digital Humanities, pp. 368389. University of Minnesota Press. http://dhdebates.gc.cuny.edu/debates/text/25.

Bartlett, J.C., \& Dalkir, K. (2020). Librarianship and beyond: The twenty-year evolution of an interdisciplinary curriculum. Education for Information, 36(2), 139-155.

Beck, A., \& Neylon, C. (2012). A vision for open archaeology. World Archaeology, 44(4), 479-497.

Berry, D.M. (2012). Introduction: Understanding the digital humanities. In Berry, D.M., (Ed.), Understanding digital humanities, pp. 1-20. Palgrave Macmillan. 
Billore, S., \& Golub, K. (2017). Digital humanities: An exploration of new programs in higher education and its meaning making by community partners. In Golub, K., Milrad, M., (Eds.), International symposium on digital humanities (DH 2016) Växjö, Sweden, November 7-8, 2016, 2021, pp. 119-125. CEUR-WS.org.

Buccellati, F., \& Kansa, E. (2016). The value of energetic analysis in architecture as an example for data sharing. Digital Applications in Archaeology and Cultural Heritage, 3(3), 91-97.

Busa, R. (1980). The annals of humanities computing: The Index Thomisticus. Computers and the Humanities, 14(2), 83-90.

Casarosa, V., Ruggieri, S., Salvatori, E., Simi, M., \& Turbanti, S. (2020). Educational ecosystems for information science: The case of the University of Pisa. Education for Information, 36(2), 119-138.

Cobb, P.J., Sigmier, J.H., Creamer, P.M., \& French, E.R. (2019). Collaborative approaches to archaeology programming and the increase of digital literacy among archaeology students. Open Archaeology, $5(1), 137-154$.

Digital humanities. (2020). In Oxford online dictionary. Retrieved October 10, 2020, from https://www. lexico.com/definition/digital_humanities.

Dillon, A. (2012). What it means to be an iSchool. Journal of Education for Library and Information Science, 267-273.

European Commission. (2016). Horizon 2020: Social sciences and humanities. Retrieved December 14, 2020, from https://ec.europa.eu/programmes/horizon2020/en/area/social-sciences-humanities.

iSchools Organization. (2020). Regions and about. Retrieved January 22, 2021, from https://ischools.org/ Regions and https://ischools.org/About.

Kansa, E., \& Kansa, S.W. (2021). Digital data and data literacy in archaeology now and in the new decade. Advances in Archaeological Practice, 9(1), 81-85.

Larsen, R.L. (2008). History of the iSchools. https://ischools.org/resources/Documents/History-of-theiSchools-2009.pdf.

Liu, A. (2013). The meaning of the digital humanities. Publications of the Modern Language Association of America, 128(2), 409-423.

Marcella, R., \& Oppenheim, C. (2020). Does education in library and information studies in the United Kingdom have a future? Education for Information, 36(4), 411-440.

Nyhan, J., \& Flinn, A. (2016). Computation and the humanities: Towards an oral history of digital humanities. Springer Series on Cultural Computing, SpringerOpen.

Robinson, L., Priego, E., \& Bawden, D. (2015). Library and information science and digital humanities: Two disciplines, joint future? [Presented paper]. 14th International Symposium on Information Science, 19-21 May 2015, Zadar, Croatia.

Roosevelt, C.H., Cobb, P., Moss, E., Olson, B.R., \& Ünlüsoy, S. (2015). Excavation is destruction digitization: Advances in archaeological practice. Journal of Field Archaeology, 40(3), 325-346.

Schreibman, S., Siemens, R., \& Unsworth, J. (2004). A companion to digital humanities. Blackwell. http://www.digitalhumanities.org/companion/.

Senchyne, J. (2016). Between knowledge and metaknowledge: Shifting disciplinary borders in digital humanities and library and information studies. In Gold, M.K., Klein, L.F., (Eds.), Debates in the Digital Humanities. University of Minnesota Press. http://dhdebates.gc.cuny.edu/debates/text/81.

Smith, N.G., Karasik, A., Narayanan, T., Olson, E.S., Smilansky, U., \& Levy, T.E. (2014). The pottery informatics query database: A new method for mathematic and quantitative analyses of large regional ceramic datasets. Journal of Archaeological Method and Theory, 21(1), 212-250.

Spiro, L. (2011). Knowing and doing: Understanding the digital humanities curriculum. [Presented paper]. Digital Humanities, Stanford University.

Sula, C.A. (2013). Digital humanities and libraries: A conceptual model. Journal of Library Administration, 53(1), $10-26$.

Sula, C.A., Hackney, S.E., \& Cunningham, P. (2017). A survey of digital humanities programs. The Journal of Interactive Technology and Pedagogy, 11. https://jitp.commons.gc.cuny.edu/a-survey-of-digitalhumanities-programs.

Terras, M. (2006). Disciplined: Using educational studies to analyse "Humanities Computing." Literary and Linguistic Computing, 21(2), 229-246. doi: 10.1093/1lc/fq1022. 
Terras, M., Nyhan, J., \& Vanhoutte, E. (2013). Defining digital humanities: A reader. Ashgate.

Vanhoutte, E. (2013). The gates of hell: History and definition of digital | humanities | computing. In Terras, M., Nyhan, J., Vanhoutte, E., (Eds.), Defining digital humanities: A reader, pp. 119-156. Ashgate.

Walsh, J.A., Zeng, M.L., Golub, K., Liu, Y.-H., Mahony, S., Park, H., Sula, C.A., Tuamsuk, K., Underwood, T., \& Wang, X. (2019). Digital humanities and the iSchool. [Presentation]. 2019 iConference.

Weingart, S.B. (2016). Submissions to DH2017 (pt. 1). https://scottbot.net/submissions-to-dh2017-pt-1/. 